\title{
The comparative behaviour of two combat boots under impact
}

\author{
Nicolas Newell ${ }^{1}$, Spyros D Masouros ${ }^{1}$, Andy D Pullen ${ }^{2}$ and Anthony MJ \\ Bull $^{1}$ \\ ${ }^{1}$ Department of Bioengineering, Imperial College London, London SW7 2AZ, United \\ Kingdom \\ ${ }^{1}$ Department of Civil \& Environmental Engineering, Imperial College London, London SW7 \\ 2AZ, United Kingdom
}

Corresponding author

Anthony MJ Bull

3.13 Royal School of Mines,

Department of Bioengineering,

Imperial College London,

London SW7 2AZ,

United Kingdom

E-mail: a.bull@imperial.ac.uk

\section{Licence Statement}

Anthony Bull has the right to grant on behalf of all authors and does grant on behalf of all authors, an exclusive licence (or non-exclusive for government employees) on a worldwide basis to the BMJ Publishing Group Ltd and its Licensees to permit this article (if accepted) to be published in IP and any other BMJPGL products to exploit all subsidiary rights, as set out in our licence. 


\begin{abstract}
Improvised explosive devices are the characteristic weapon of conflicts in Iraq and Afghanistan. While little can be done to mitigate against the effects of blast in free field explosions, scaled blast simulations have shown that the combat boot can attenuate the effects on vehicle occupants of anti-vehicular (AV) mine blasts. Although the combat boot offers some protection to the lower limb, its behaviour at the energies seen in AV-mine blast has not been documented previously.

The sole of eight same-size combat boots from two brands currently used by UK troops deployed to Iraq and Afghanistan were impacted at energies of up to $518 \mathrm{~J}$, using a spring assisted drop rig. The results showed that the Meindl Desert Fox combat boot consistently experienced a lower peak force at lower impact energies and a longer time to peak force at higher impact energies when compared with the Lowa Desert Fox combat boot. This reduction in the peak force and extended rise time, resulting in a lower energy transfer rate, is a potentially positive mitigating effect in terms of the trauma experienced by the lower limb.

Currently, combat boots are tested under impact at the energies seen during heel strike in running. Through the identification of significantly different behaviours at high loading, this study has shown that there is rationale in adding the performance of combat boots under impact at energies above those set out in international standards to the list of criteria for the selection of a combat boot.
\end{abstract}

Keywords. Blast injury, biomechanics, high strain rates, impact testing, footwear 


\section{What is already known on this subject}

Combat boots offer protection to surrogate lower limbs in AVmine blasts

Current test standards test combat boots at energies seen during heel strike in running $(5 \mathrm{~J})$

Tests performed on skateboarding shoes have shown that the mechanical behaviour of footwear varies at different energy levels

\section{What this study adds}

The behaviour of the combat boot was quantified at impact utilising energies 100 times greater than those in current test standards

- The behaviour of two brands of combat boot was shown to be different across energies at high energy impact, but not at low energy impact 


\section{INTRODUCTION}

Improvised explosive devices (IEDs) have become a characteristic weapon used by insurgents in Iraq and Afghanistan accounting for 39.2\% (2546/6492) of fatalities since conflicts began, making it the leading cause of death and injury to coalition troops in Iraq and Afghanistan. ${ }^{1-5}$ While IEDs are a significant threat in current conflicts, they also present longterm socio-economic implications during humanitarian efforts post-conflict. ${ }^{6}$ IED attacks can be categorised into two distinct groups, open (free field) and closed (anti-vehicular, AV). Due to the unprotected nature of open landmine blasts, resultant fractures of the lower extremities are so severe that limb salvage is not possible. However, fractures seen in AV-mine blasts are often less severe presenting the opportunity for the potential role of mitigation technologies for occupants of vehicles subjected to mine blast.

Scaled simulations of $\mathrm{AV}$-mine blasts have revealed that the combat boot can attenuate the forces imparted to the lower limb as well as increase the time to peak force. ${ }^{7}$ Unlike casualties from free field explosions, vehicle occupants in a mine blast are not subjected to a blast wave; rather, they are subjected to high impulse loading caused by rapid local deformation of the floor of the vehicle. ${ }^{8}$

Current international protocols test athletic footwear under impact using gravitydriven devices that impart an energy that simulates heel strike during running (5 Joules). ${ }^{9-12}$ However, impact tests performed on the soles of skateboarding shoes at energies of up to $44 \mathrm{~J}$ have shown that the shock-absorbing characteristics of different shoes vary at different

energies, ${ }^{13}$ suggesting that it is of value to test footwear up to the energies expected to be seen during use.

The aim of this study was to compare the behaviour of different combat boots currently deployed to the UK armed forces under impact. 


\section{MATERIALS AND METHODS}

Tests were performed using an Instron Dynatup 9250-HV (Instron, High Wycombe, UK) spring-assisted drop-weight rig (Figure 1). Eight new, same-size combat boots, from the two most commonly used by UK troops brands, were used in this study; namely Meindl Desert Fox (Lucas Meindl GmbH and Co, Kirchanschoring, Germany) and Lowa Desert Fox combat boot (Lowa Sportschuhe GmbH, Jetzendorf, Germany). The upper part of each boot was cut away to leave the insole, insole board, midsole and outsole. The key geometric features of the two brands of combat boot are shown in Table 1.

$<$ Insert Figure 1>

\begin{tabular}{ccccccc}
\hline Brand & Insole & Heel pad & Insole board & Midsole & Outsole & Total \\
\hline Meindl Desert Fox & 3.08 & 2.54 & 6.85 & 23.41 & 4.42 & $\mathbf{4 0 . 3 0}$ \\
Lowa Desert Fox & 3.10 & - & 5.66 & 18.80 & 10.01 & $\mathbf{3 7 . 5 7}$
\end{tabular}

Table 1 - Thickness of each material layer at the centre of the heel of the Meindl Desert Fox and Lowa Desert Fox combat boot. All measurements are in $\mathrm{mm}$ and are an average of 3 measurements made with digital callipers with resolution of $0.01 \mathrm{~mm}$.

Each sample was placed on a flat solid-steel surface and impacted at the heel with a $7.45 \mathrm{~kg}$ impactor with a $50 \mathrm{~mm}$ diameter head to simulate a heel. Markers were used on the solid steel plate to ensure that the samples were positioned at the same place before each test, thus ensuring that the tup impacted at the same location on the heel. Each boot was impacted at energies of $7.9 \pm 0.4,15.7 \pm 0.6,45.2 \pm 0.6,137 \pm 0.3$ and $518 \pm 6 \mathrm{~J}$, the last being the energy produced when the impact occurred at approximately $12 \mathrm{~m} / \mathrm{s}$. This velocity was chosen because AV-mine blast tests have shown that vehicle floor deformation can reach velocities of $12 \mathrm{~m} / \mathrm{s}^{14}$

The samples were given a 15 minute relaxation period between tests; preliminary repeated tests of the same sole at $7.9 \mathrm{~J}$ showed that a 15 minute relaxation time was adequate to give a repeated response (within 3\%) in terms of peak force and time to peak force. Between the tests at 45.2 and $137 \mathrm{~J}$ the boots were impacted again at $7.9 \mathrm{~J}$ and the resulting behaviour was compared to the original in order to assess whether any permanent changes had occurred in the meantime. All tests were conducted at $22 \pm 1{ }^{\circ} \mathrm{C}$.

The drop-weight rig is equipped with a sensor to measure the velocity of the tup prior to impact and to trigger data collection. The height of this was adjusted for each sample to ensure the data started to be recorded just a fraction before the tup first came in contact with the sample. The impactor had a built-in force transducer $(222 \mathrm{kN} \pm 1 \%)$, which recorded the 
force history directly. Sampling was set at a rate of $330 \mathrm{kHz}$. The velocity during impact was calculated by integrating the acceleration data, which was calculated from the force history data and the impactor mass. Boot deformation was quantified through compressive displacement at the point of impact; this was calculated by integrating the velocity history data. The energy absorbed by the sole was calculated assuming it being equal to the loss in kinetic energy of the impactor. The latter was calculated for each test from initial and rebound velocities of the impactor, which were determined using high-speed video (Phantom V12.1, frame rate: $4000 \mathrm{fps}$, resolution: $1280 \times 800$ ).

Differences between samples in peak force, displacement at peak force, time to peak force and percentage energy absorbed were compared for differences using a two-tailed unpaired Student's $t$-test with the significance level set at 0.05 .

\section{RESULTS}

All samples of Meindl Desert Fox combat boot fractured at $518 \mathrm{~J}$ while all samples of the Lowa Desert Fox combat boot stayed intact. At impact energies lower that this, no damage was seen to either combat boot. The results from the repeated test at $7.9 \mathrm{~J}$ were not statistically different to the initial impacts at $7.9 \mathrm{~J}$ in terms of peak force, time to peak force and maximum deformation $(p=0.12)$. Average force-time and force-displacement traces for the 8 tests performed at $45.2 \mathrm{~J}$ can be seen in Figure 2.

\section{$<$ Insert Figure 2>}

Average values from the tests are summarised in Figure 3. The peak force exhibited by the Meindl Desert Fox combat boot is significantly lower $(p<0.05, n=8)$ than that exhibited by the Lowa Desert Fox combat boot at all energy levels except for at $137 \mathrm{~J}$.

The displacement at peak force exhibited by the Meindl Desert Fox combat boot is significantly higher $(p<0.05, n=8)$ than that exhibited by the Lowa Desert Fox combat boot at all energy levels. The time to peak force exhibited by the Meindl Desert Fox combat boot is significantly higher $(p<0.05, n=8)$ than that exhibited by the Lowa Desert Fox combat boot at all energy levels apart from at 7.9 J. The energy absorbed by the Meindl Desert Fox combat boot is similar to that exhibited by the Lowa Desert Fox combat boot at all energy level apart from at $7.9 \mathrm{~J}$ where it is significantly greater.

\section{$<$ Insert Figure 3>}




\section{DISCUSSION}

$\mathrm{AV}$-mine blast tests have shown that vehicle floor deformation can reach velocities of $12 \mathrm{~m} / \mathrm{s} .{ }^{14}$ However, floor behaviour depends upon the vehicle, and the type and placement of the mine. Therefore, there is a range of velocity and acceleration time responses of the deforming floor. The aim of this work was not to recreate these specific responses on a boot; rather, it aimed at comparing the two brands of combat boot under impact at ever increasing velocities until they were compromised. Therefore, impact tests were performed at up to one hundred times the energy indicated by current test standards to assess the behaviour of the two most common types of combat boots currently (2010) deployed to UK troops.

At the highest energy level (518 J) the Lowa Desert Fox combat boot did not fracture, while fracture was seen in all 8 of the Meindl Desert Fox combat boot samples. Fracture was occurring consistently in the Meindl insole (Figure 4). Fracturing may render the boot unserviceable, but serviceability is unlikely to be an important issue following an impact event at this energy level. The mechanical process of fracturing itself dissipates energy, which may result in a significant reduction in energy transferred to the lower limb. It is possible for a boot after a blast to be structurally intact while the foot inside is so damaged that it is not possible for it to be surgically salvaged. ${ }^{15}$

\section{$<$ Insert Figure 4>}

At the test performed under 45.2 J, the Meindl Desert Fox combat boot transferred a smaller force over a longer time than the Lowa Desert Fox combat boot. The first $3 \mathrm{~ms}$ of the force-time curve and the initial $8 \mathrm{~mm}$ of deflection shown by the force-displacement curve shown in Figure 2 are non-linear. This is due to the back of the heel being slightly elevated above the solid steep plate until enough force is applied to cause contact between the solid steel plate and the back of the heel. At $137 \mathrm{~J}$, while the two combat boots transfer a similar peak force, the Meindl Desert Fox combat boot transfers the force over a longer period of time than the Lowa Desert Fox combat boot. The resulting reduced energy transfer rate is likely to be beneficial in reducing the trauma experienced by the lower limb. These differences in performance could be attributed, at least partly, to the differences in geometry of the combat boots. The Meindl Desert Fox combat boot is $2.73 \mathrm{~mm}$ thicker than the Lowa Desert Fox combat boot at the heel and has a $4.61 \mathrm{~mm}$ thicker mid-sole layer (Table 1). Wilson (2006) showed that maximum deceleration has a negative linear relationship with thickness in polymers, rendering thickness a key factor in determining the performance of footwear under impact. ${ }^{9}$ 
One must be cautious when extrapolating these results to determine which combat boot will offer most protection in an $\mathrm{AV}$-mine blast, as the experiment presented here is not attempting to replicate the battlefield. Rather, this study assesses whether different combat boots behave differently at ever increasing energy levels by testing at impact velocities higher than those used in current test standards. ${ }^{11,12}$ An AV-mine blast produces rapid displacement of the floor of the vehicle, which impacts the soles of the combat boots worn by the occupants in a predominantly axial direction, forcing their legs upward, away from the vehicle floor. While the velocity of the floor in an AV-mine blast can be measured from live blast experiments, it is difficult to estimate the energy of the impact on the combat boot as there are a number of unknown influential variables, such as the equivalent mass of the vehicle floor, the size of the explosive, the depth of burial of the explosive and the vehicle structural design itself. Therefore, the methods used to impact the combat boots in this study are rather different to the situation seen in the battlefield; the boots were impacted directly on the insole against a rigid surface at ever increasing velocities until fracture was seen. The reason for selecting this method for testing is that current test standards simulate heel strike during running, where the tup represents the heel and the rigid surface represents the floor. While the energy being transferred to the sole of the combat boot in an AV-mine blast is likely to be higher than the $518 \mathrm{~J}$ used here, the boot is not constrained against a rigid surface in a vehicle and therefore the maximum strain and strain rate of the boot material during an $\mathrm{AV}$-mine blast is likely to be within the range tested in this study. Other effects on the boots, such as wear, the temperature at impact, direction of impact and the interaction with the human could also have an influence on the results presented here.

\section{CONCLUSIONS}

This article presented an experimental method which is simple, repeatable and allows the evaluation of the behaviour of different combat boots under ever increasing impact velocities. The tests demonstrated that the behaviour of the combat boot varies under impact over a range of energy levels, and there were significant differences in performance of two combat boots deployed in the current theatres of operation. The differences in performance seen in the two combat boots used in this study at high and low strain rates demonstrates the necessity to carry out tests at high energies such as those seen in AV-mine blast on current and future combat boot designs. However, further work in assessing the role of the boot in reducing injury risk to the lower limb due to AV-mines is required; this could include numerical exercises, which would utilise the results from the current study for validation purposes.

Although the effectiveness of a combat boot on reducing lower limb injury risk during an AV-mine blast has not been quantified rigorously, this study has shown that there is rationale in adding the performance of combat boots under impact at energies above those set out in international standards to the list of criteria for the selection of a combat boot. ${ }^{11,12}$ 


\section{FUNDING}

This project was part-funded by a BBSRC CASE studentship.

\section{COMPETING INTEREST DECLARATION}

The authors declare that they have no competing interests.

\section{REFERENCES}

1. Owens BD, Kragh JF Jr., Wenke JC, Macaitis J, Wade CE, Holcomb JB. Combat wounds in operation Iraqi Freedom and operation Enduring Freedom. J Trauma 2008;64:295-9.

2. Ramasamy A, Harrisson SE, Clasper JC, Stewart MP. Injuries from roadside improvised explosive devices. J Trauma 2008;65(4):910-4.

3. Ramasamy A, Harrisson SE, Stewart MPM, Midwinter M. Penetrating missile injuries during the Iraqi Insurgency. Ann Roy Coll Surg 2009;91:551-8.

4. Ramasamy A, Harrisson SE, Lasrado I, Stewart MPM. A review of casualties during the Iraqi insurgency 2006 - A British field hospital experience. Injury 2009;40:493-7.

5. iCasualties. Iraq coalition casualty count. Georgia: iCasualties. http://icasualties.org/ (accessed 20 May 2010).

6. Ramasamy, A, Hill AM, Masouros SD, Gordon F, Clasper JC, Bull AMJ. Evaluating the effect of vehicle modification in reducing injuries from landmine blasts. An analysis of 2212 incidents and its application for humanitarian purposes. Accid Anal Prev In Press.

7. Manseau J, Keown M, editors. Development of an assessment methodology for lower leg injuries resulting from anti-vehicular blast landmines. IUTAM proceedings on impact biomechanics: From fundamental insights to applications; 2005; Dublin, Ireland: Springer, Netherlands.

8. Ramasamy A, Masouros SD, Newell N, et al. In-vehicle extremity injuries from improvised explosive devices: current and future foci. Phil Trans R Soc B 2011;366: 160-70.

9. Wilson M. Understanding shock absorption. SATRA Bulletin International 2006:10-2.

10. Wilson M. Shock absorbing properties of lightweight solings. SATRA Bulletin International 1984:88-9. 
11. ASTM F1614-99. Test Method for Shock Attenuating Properties of Materials Systems for Athletic Footwear. American Society for Testing Materials; 1999.

12. BS EN ISO 20344: 2004. Personal protective equipment - test methods for footwear. British Standard; 2004.

13. Determan J, Vevitt M, Frederick EC. Measuring the shock attenuation properties of skateboarding shoes. Footwear Science 2009;1:126-8.

14. Wang JJ, Bird R, Swinton B, et al. Protection of Lower Limbs against Floor Impact in Army Vehicles Experiencing Landmine Explosion. J Battlefield Tech 2001;4:11-5.

15. Chaloner E, McMaster J, Hinsley D. Principles and problems underlying testing the effectiveness of blast protective footwear. J R Army Med Corps 2002;148:38-43.

\section{LIST OF FIGURES}

Figure 1: Schematic of the Instron Dynatup 9250-HV and the experimental setup.

Figure 2: Average results from the tests at 45.2 J. The grey shading indicates \pm 1 S.D. $(n=8)$.

Figure 3: Average values of (a) peak force (b) displacement at peak force, (c) time at peak force and (d) percentage energy absorbed for each specimen ( $\mathrm{n}=8$ samples) across the range of imparted energies. *denotes significant difference $p<0.05$.

Figure 4: Photographs of the insole of the Meindl Desert Fox Combat boot pre and post impact at the highest energy level (518J). The black arrow in the post impact photograph points to a fracture line on the insole. Fractures like this were seen in all Meindl samples after tests at this energy level.

\section{LIST OF TABLES}

Table 1 - Thickness of each material layer in the Meindl Desert Fox and Lowa Desert Fox combat boot. All measurements are in $\mathrm{mm}$ and are an average of 3 measurements made with digital callipers with resolution of $0.01 \mathrm{~mm}$. 


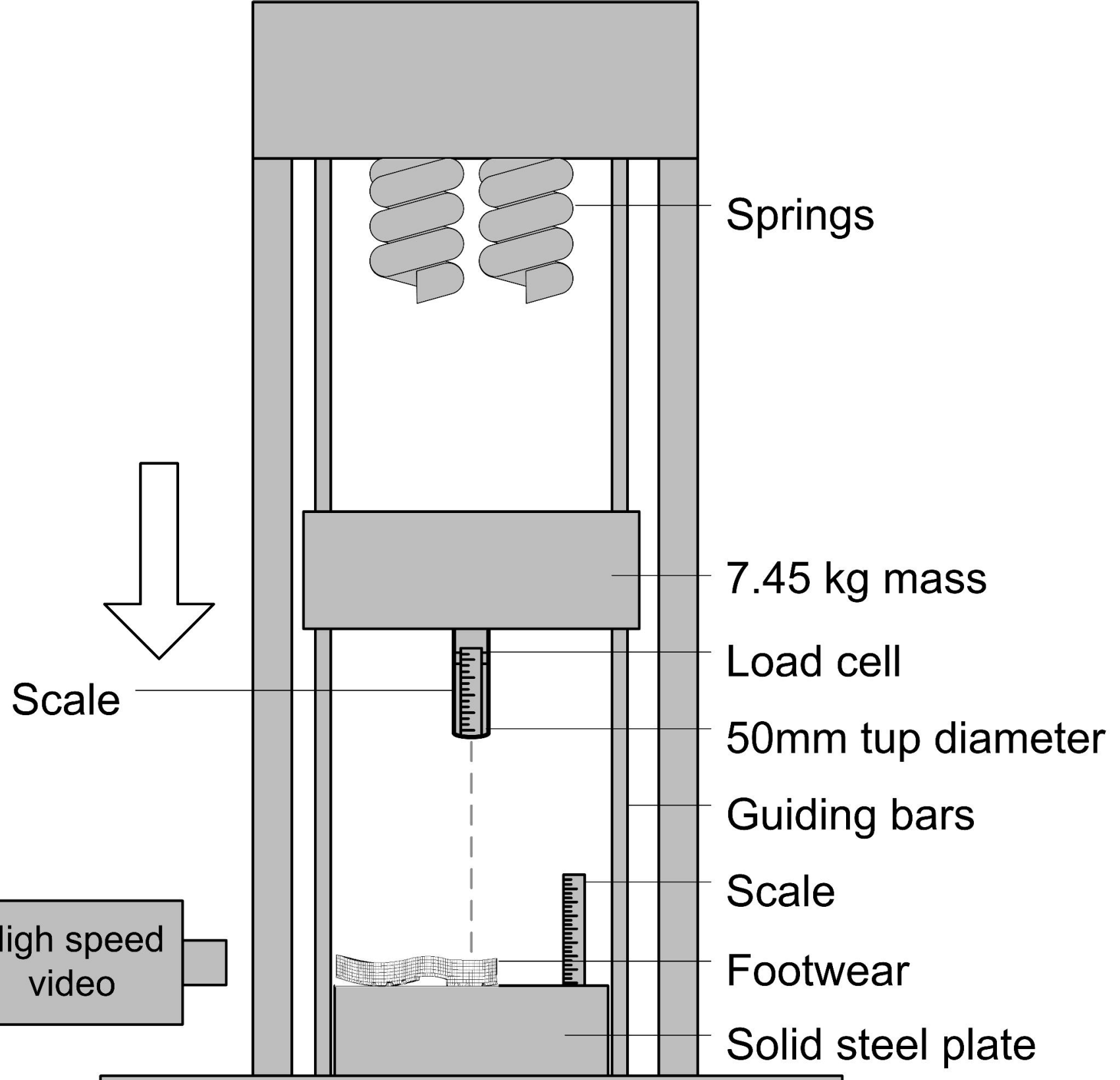




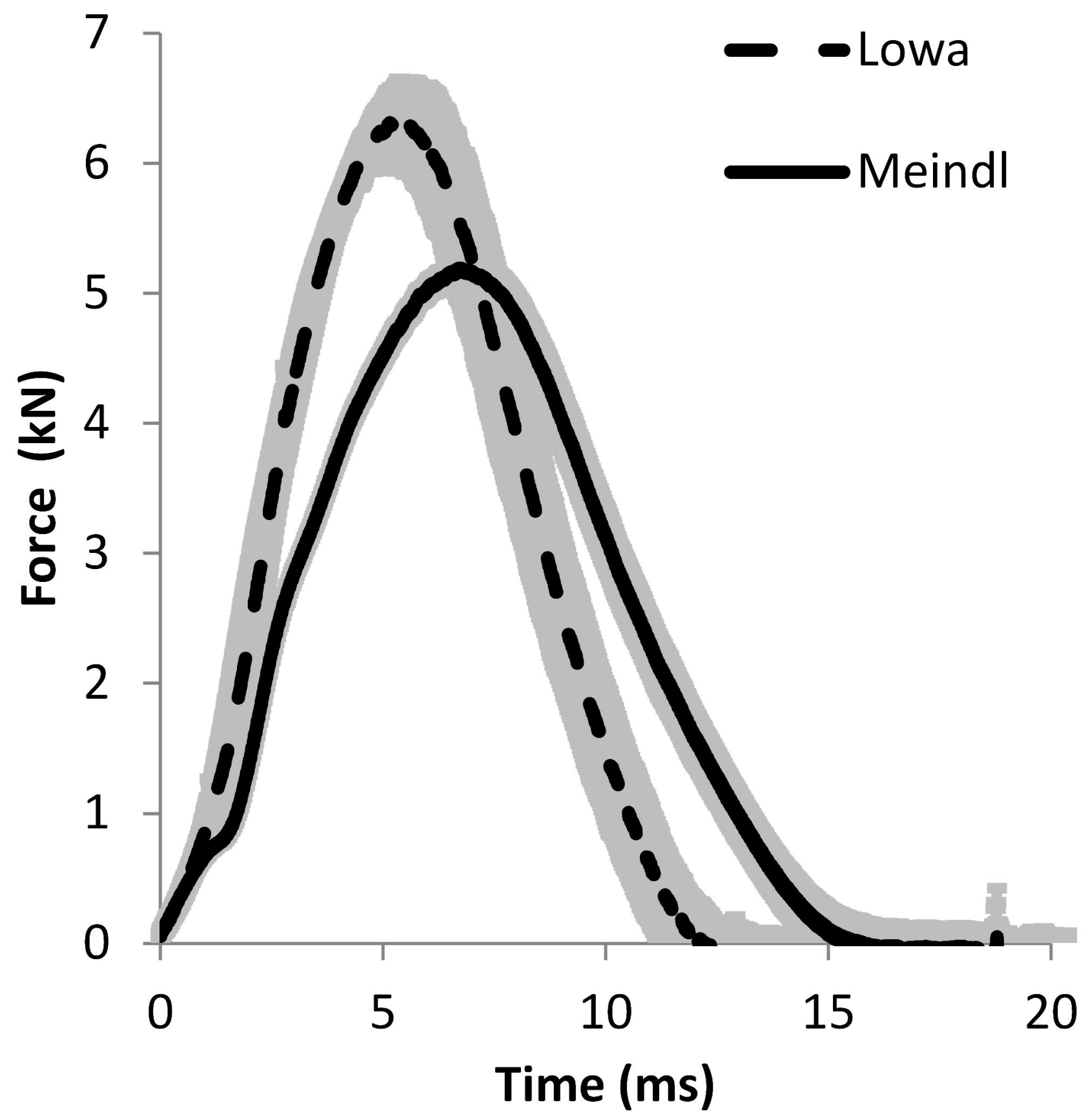




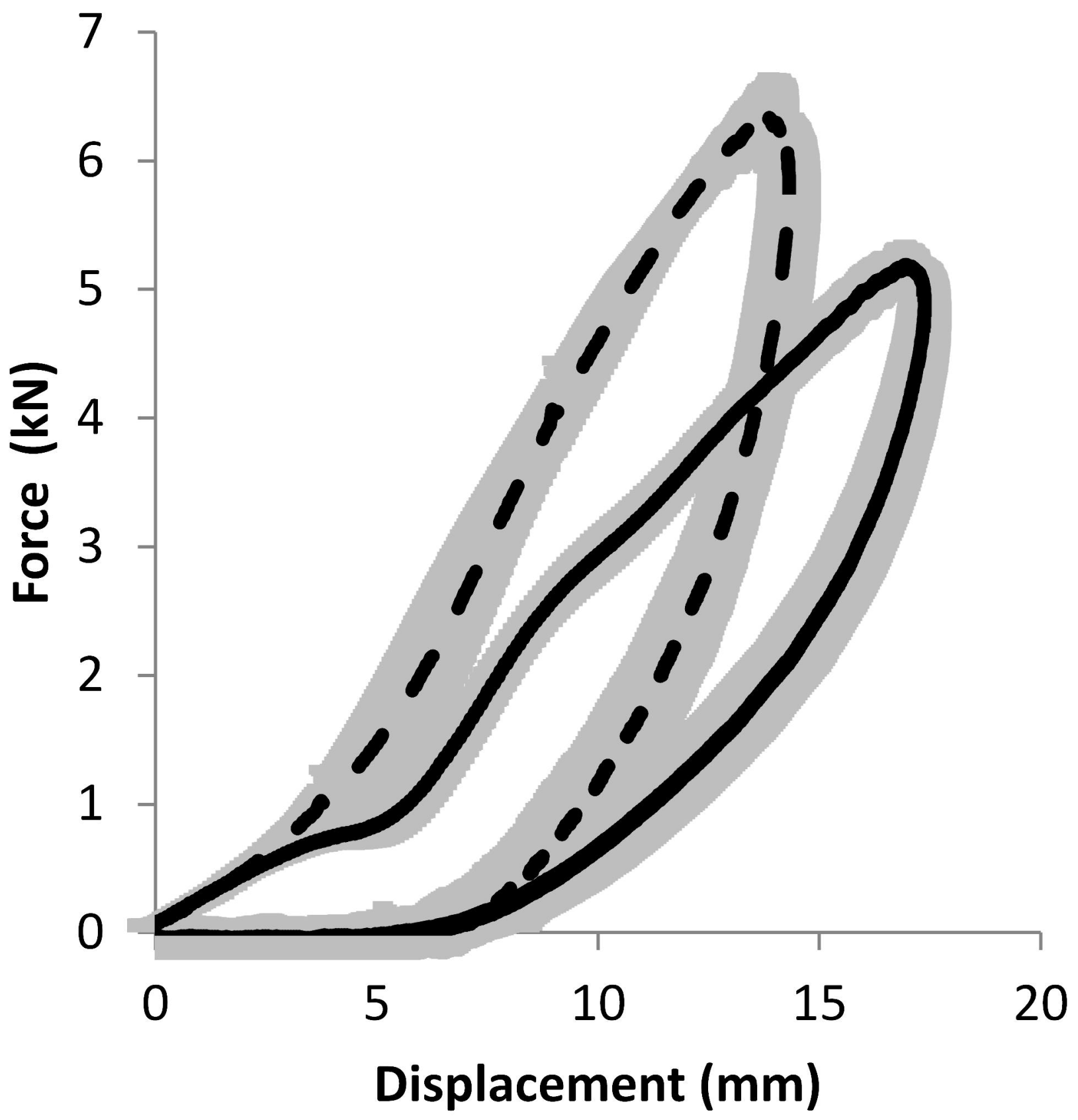




\section{$\square$ Meindl $\quad \square$ Lowa}

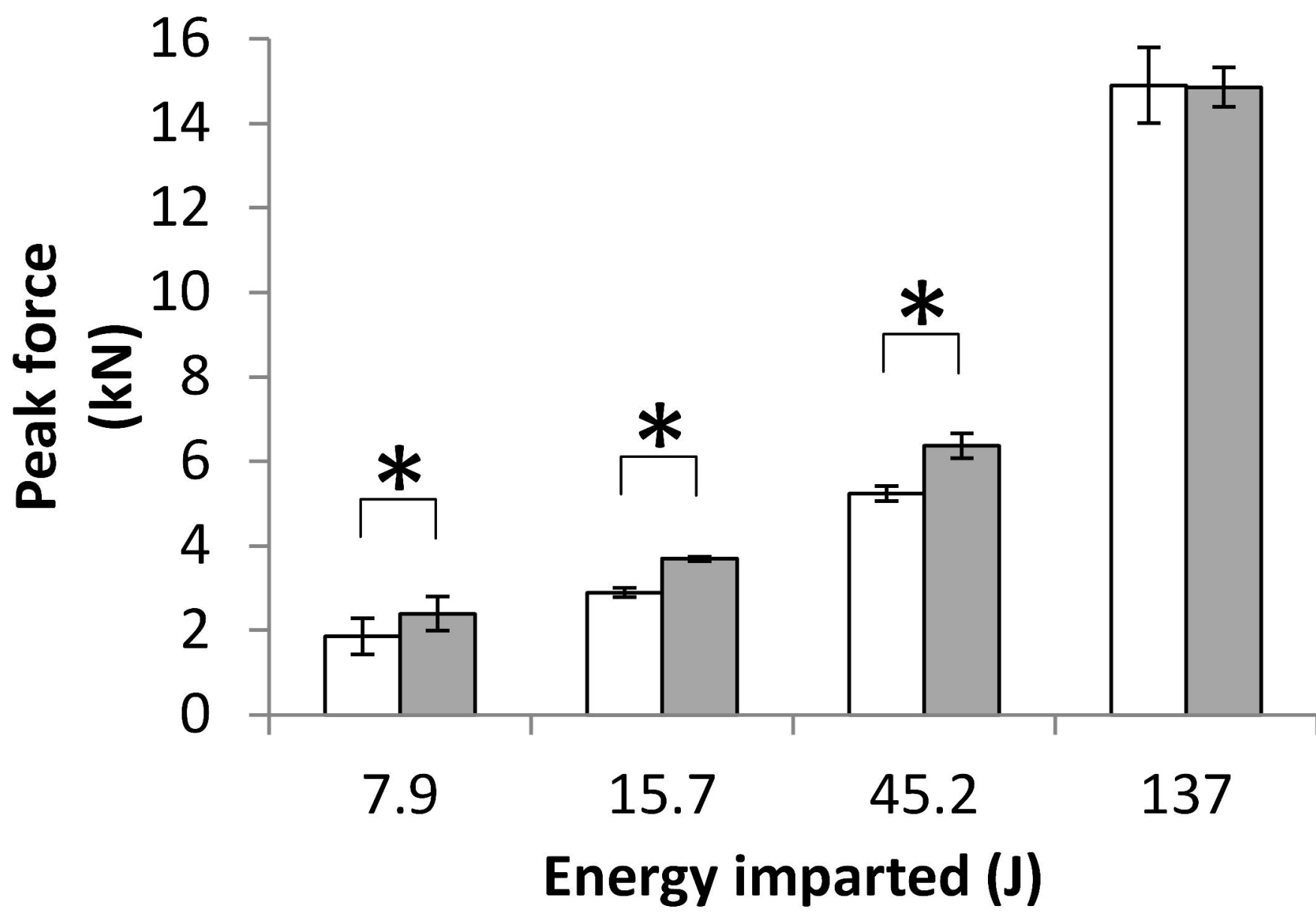




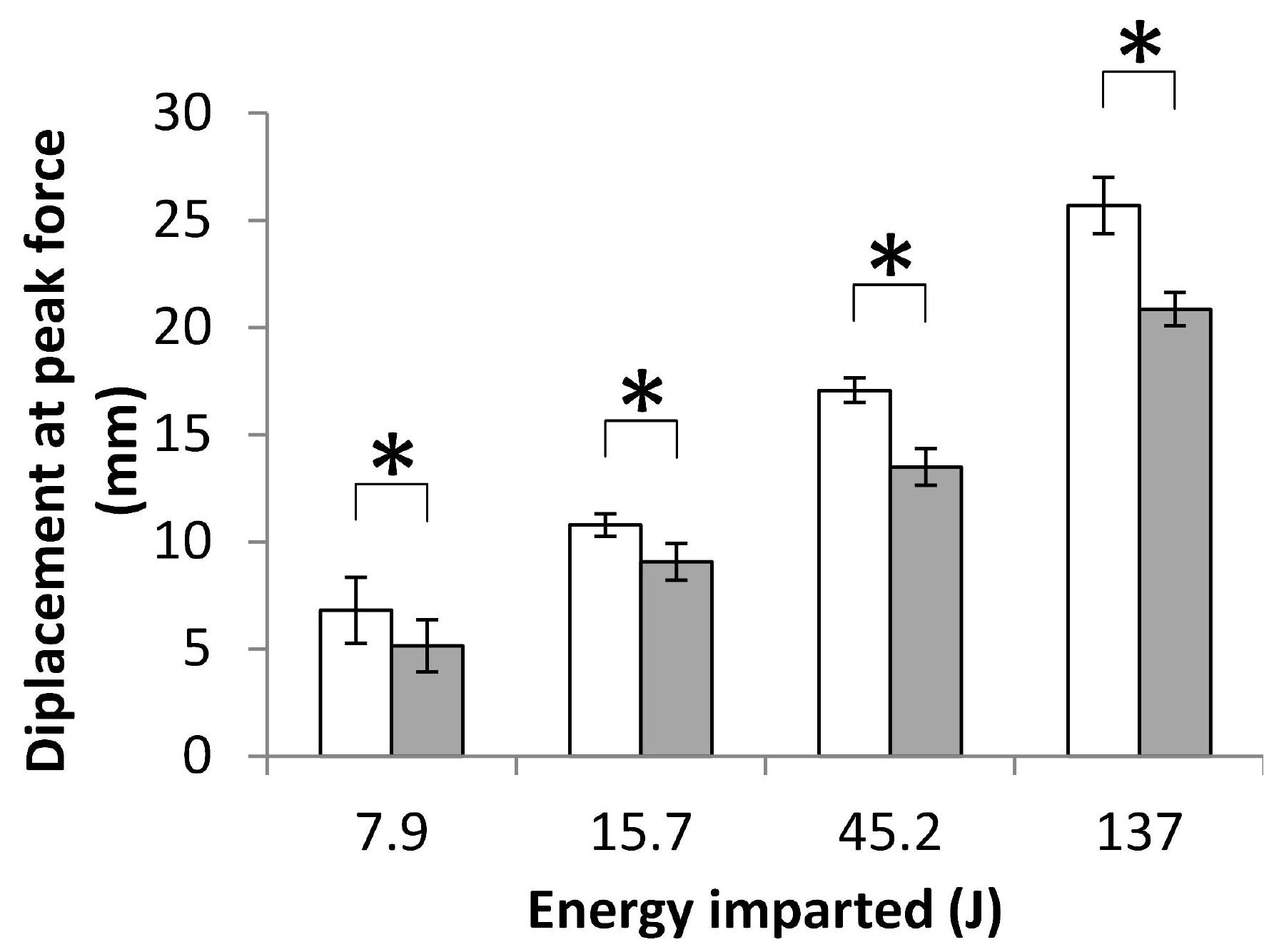




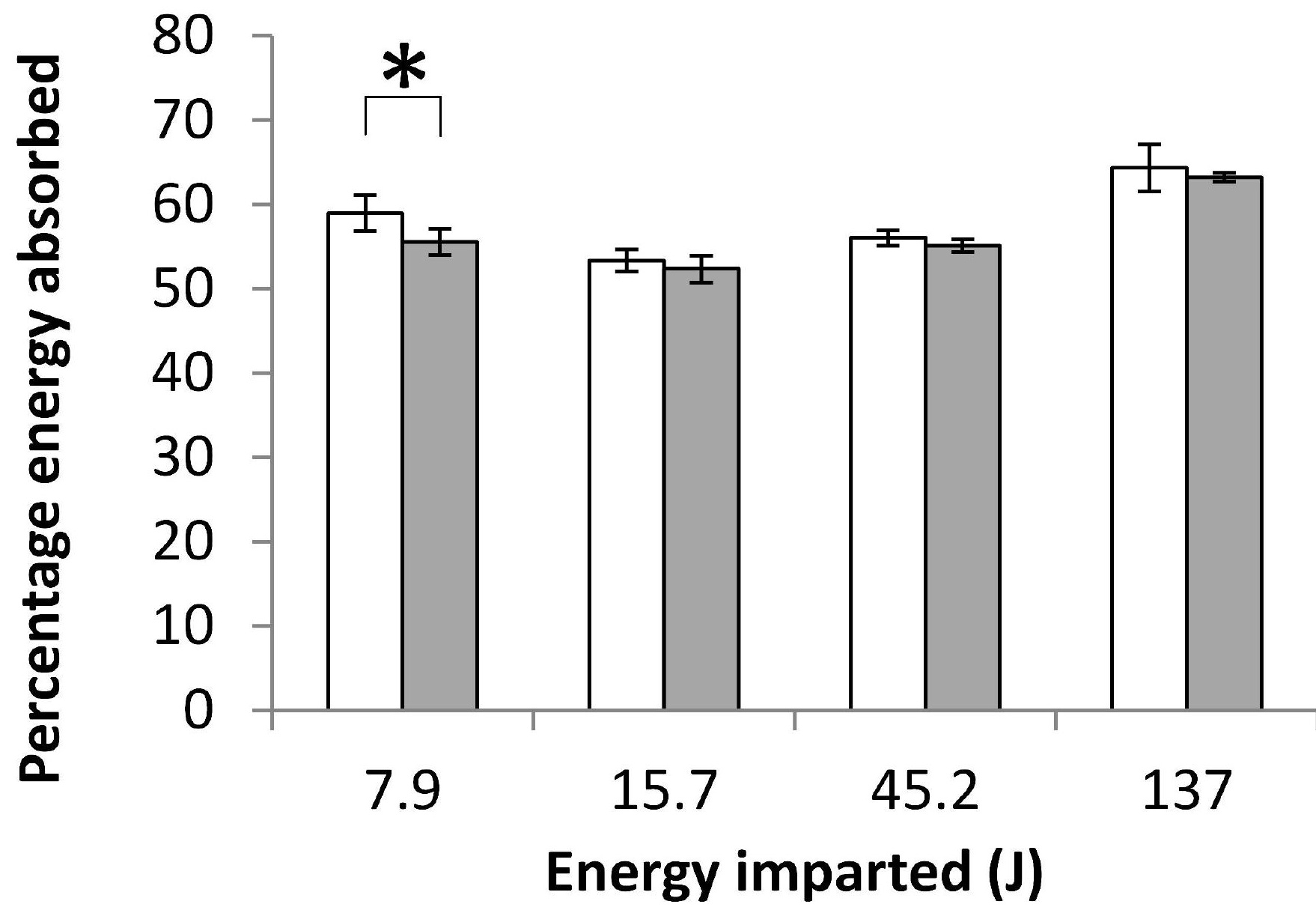




\section{$1 \mathrm{~cm}$}

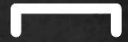

\section{Pre-impact}

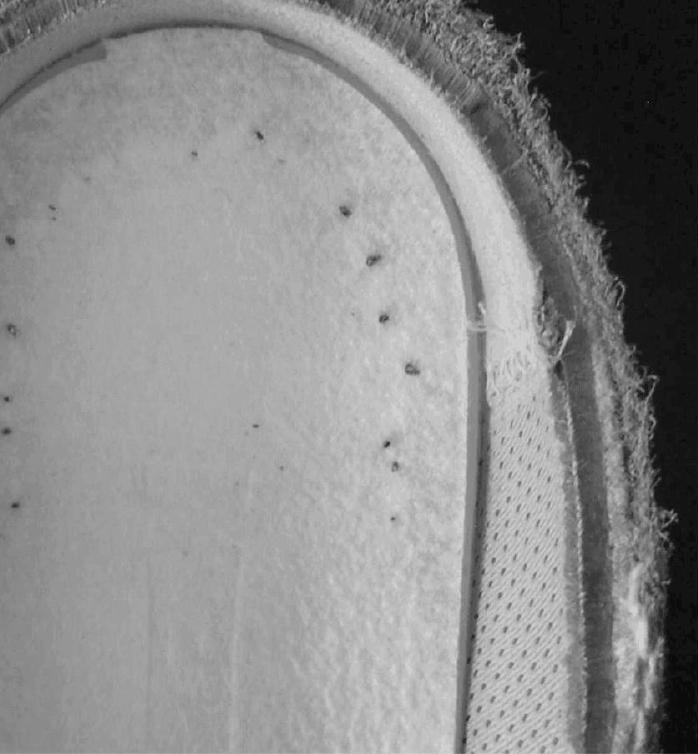


$1 \mathrm{~cm}$

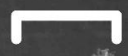

whom

Post-ímpact

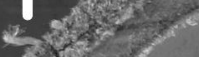

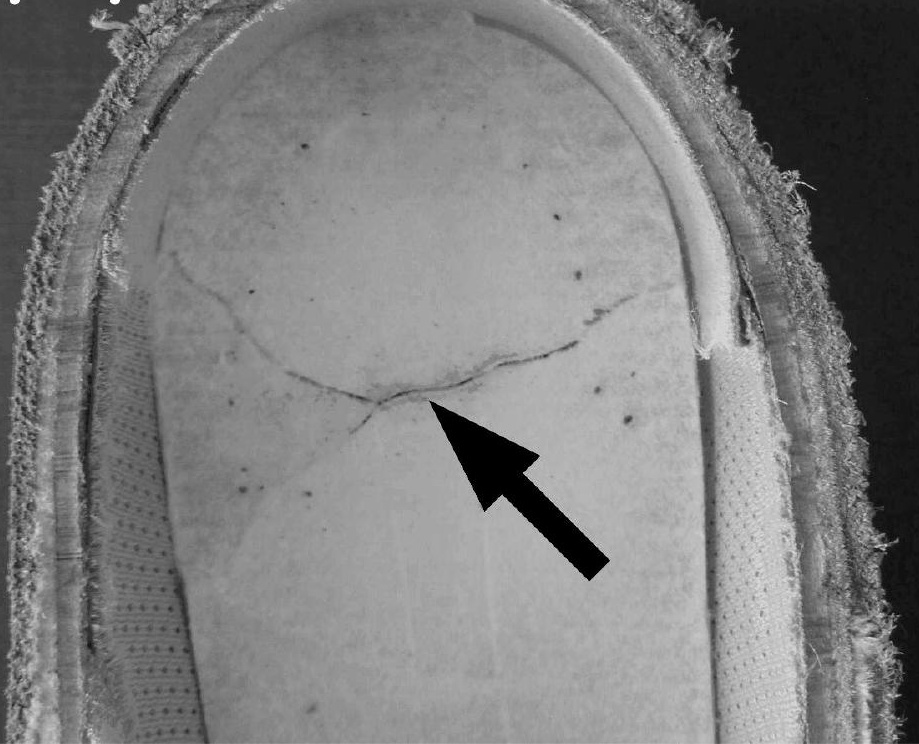

